\title{
DEFINITION OF TOLERABLE SOIL EROSION VALUES ${ }^{(1)}$
}

\author{
G. SPAROVEK $K^{(2)} \&$ Q. J ONG VAN LIER $\mathbf{R}^{(3)}$
}

\begin{abstract}
SUMMARY
Although the criteria for defining erosion tolerance are well established, the limits generally used are not consistent with natural, economical and technological conditions. Rates greater than soil formation can be accepted only until a minimum of soil depth is reached, provided that they are not associated with environmental hazard or productivity losses. A sequence of equations is presented to calculate erosion tolerance rates through time. The selection of equation parameters permits the definition of erosion tolerance rates in agreement with environmental, social and technical needs. The soil depth change that is related to irreversible soil degradation can be calculated. The definition of soil erosion tolerance according to these equations can be used as a guideline for sustai nable land use planning and is compatible with expert systems.
\end{abstract}

Index terms: Erosion tolerance, soil depth change, land use planning.

\section{RESUMO: DEFINIÇÃO DE VALORES TOLERÁVEIS DE EROSÃO}

Apesar dos critérios utilizados para a definição de valores toleráveis de erosão estarem bem defi nidos, os li mites geral mente util izados não são consistentes com as condições naturais, econômi cas ou tecnológi cas. Val ores superiores à taxa de renovação do sol o podem ser aceitos apenas até ser alcançada uma profundidade mínima do solo, associado ao fato de não poder ser aceita a degradação ambiental ou a perda de produtividade das culturas. É apresentada uma seqüência de equações para o cál cul o da erosão tol erável ao longo do tempo. A sel eção dos parâmetros das equações permi tea definição da tol erância de perda de solo em concordância com os condici onantes ambientais, sociais etécni cos. A alteração da profundidade do sol o que serelaciona com a sua degradação irreversível podeser cal culada. A defini ção da tolerância de perda de solo por estas equações pode servir de subsídio para o planejamento racional e sustentável do uso das terras e écompatível com sistemas automatizados.

Termos de indexação: tol erância de perda de solo, alteração de profundidade do solo, planejamento do uso da terra.

\footnotetext{
(1) Paper presented at the $24^{\text {th }}$ Brazilian Soil Science Congress, Goiânia, 1993. Received for publication in J uly 1996 and approved in April 1997.

(2) Professor, Department of Soil Science, Universidade de São Paulo, Caixa Postal 9, CEP 13418900 Piracicaba (SP), Brazil. CNPq researcher. Email: gsparove@carpa.ciagri.usp.br

(3) Professor, Department of Soil Science, Universidade Federal do Rio Grande do Sul, Caixa Postal 776, CEP 90001970 Porto Alegre (RS), Brazil. CNPq researcher. Email: qdjvlier@vortex.ufrgs.br
} 


\section{INTRODUCTION}

Soil is an essential natural resource, available in limited quantities. Under natural conditions, material is removed from the soil surface mainly by the action of water and/or wind in a process called erosion, the main natural soil depth reducing factor. If the soil material is deposited lower, on the foot of a hill or mountain, concave slope, flood plain or other trapping position, without theinterference of streams or rivers, it is called colluvium. If it is taken away by a river and deposited further on a flood plain, it is called alluvium. Colluvium and alluvium both are forms of sedimentation, a soil depth increasing factor. At the lower boundary of the soil, rocks are weathered and incorporated into the soil. This is part of the process called soil formation and also a soil depth increasing factor. I f the erosion rate equals the soil depth increase rate, caused by the sum of soil depth increasing factors, soil depth does not vary with time. In cases where the erosion rate is smaller than the soil depth increase rate, soils become deeper with time. This is the casefor most well drained densely vegetated soils, especially those from tropical regions. However, agriculture can substantially modify soil formation and erosion/sedimentation rates. With the removal of thenatural soil cover and its replacement by crops, thesoil's protection against the action of rain and wind will be absent or less efficient. As a consequence, the erosion rate increases and may become greater than thesoil depth increase rate, resulting in soil depth loss.

The use and management of soils must consider how to preserve it from excessive depth loss and consequent degradation of its physical, chemical and biological properties. However, information on how to determine the erosion tolerance is limited. An important step forward on the issue was made when Stamey \& Smith (1964) suggested a conceptual model emphasizing several points to be considered for determining erosion tolerance: "It should: 1) provide for the permanent preservation or improvement of soil as a resource, 2) be adaptable to the erosion and renewal rates of any soil characteristics, 3) be a function of position, 4) be applicable regardless of the cause of erosion or renewal and 5) be based on the assumption that if any soil property is available in excess of present or predictable future requirements, it is tolerable to use the excess". They developed a general mathematical equation for erosion tolerance considering these points. Later, Skidmore (1982) added that erosion tolerance should weigh erosion from the standpoint of pollution and other environmental concerns and developed an equation for erosion tolerance as a function of the actual soil depth.

Considering that some of the above criteria, like available excess and environmental concern, aretime dependent, fixed values for soil erosion tolerance (Grossman \& Berdanier, 1982) can only be valid for limited time. This is confirmed by the fact that those values are al most al ways greater than the estimated soil formation rates (McCormack et al., 1982).
The objective of this paper was to present equations for determining tolerable erosion rates according to the conditions stated by Stamey $\&$ Smith (1964) and Skidmore (1982) and show some examples of its applicability.

\section{METHODS}

In order to establish the relationship between time and tolerable erosion rates some parameters were defined. The change of actual erosion rate $\left(E_{0}, \mathrm{~mm} \mathrm{y}^{-1}\right)$ to a new erosion rate $E_{1}\left(\mathrm{~mm} \mathrm{y}^{-1}\right)$ can be mathematically described as follows:

$$
\mathrm{E}_{\mathrm{t}}=\mathrm{E}_{0}+\left(\mathrm{E}_{1}-\mathrm{E}_{0}\right)\left(\frac{\mathrm{t}-\mathrm{t}_{0}}{\mathrm{t}_{1}-\mathrm{t}_{0}}\right)^{\mathrm{m}} ; \mathrm{t}_{0} \leq \mathrm{t} \leq \mathrm{t}_{1} ; \mathrm{m}>0
$$

where $E_{t}\left(m m y^{-1}\right)$ is the erosion rate at timet $(y), t_{0}$ $(y)$ is the actual time, $t_{1}(y)$ is the time when $E_{1}$ is reached and $m$ is an exponential factor allowing the modification of the shape of the $E_{t}$ curve. Usually, the actual erosion rate $\mathrm{E}_{0}$ is found to be too high and will have to be reduced to a more acceptable $\mathrm{E}_{1}$ erosion rate. At $t_{1}$, new conditioning factors might be determined and consequently it might be decided that erosion rate $E_{2}$ is to be reached at some future time $t_{2}$. In this way, $n$ different intervals may be defined. Indexing $\mathrm{i}(\mathrm{l} \leq \mathrm{i} \leq \mathrm{n})$, according to equation (1):

$$
E_{t}=E_{i-1}+\left(E_{i}-E_{i-1}\right)\left(\frac{t-t_{i-1}}{t_{i}-t_{i-1}}\right)^{m_{i}} ; t_{i-1} \leq t \leq t_{i} ; m_{i}>0
$$

Soil depth change $(\Delta z, \mathrm{~mm})$ will occur according to the difference between soil depth increase rates $(P$, $\mathrm{mm} \mathrm{y}^{-1}$ ) and erosion rates integrated along time:

$$
\Delta \mathrm{z}=\mathrm{p}-\mathrm{e}
$$

where:

$$
\mathrm{p}=\int_{\mathrm{t}_{0}}^{\mathrm{t}} \mathrm{Pdt}=\int_{\mathrm{t}_{0}}^{\mathrm{t}} \mathrm{Fdt}+\int_{\mathrm{t}_{0}}^{\mathrm{t}} \mathrm{S} \mathrm{dt}
$$

with $\mathrm{F}$ being the soil formation rate due to rock weathering ( $\left.\mathrm{mm} \mathrm{y}^{-1}\right)$ and $\mathrm{S}$ being the sedimentation rate $\left(\mathrm{mm} \mathrm{y}^{-1}\right)$, and

$$
\mathrm{e}=\int_{\mathrm{t}_{0}}^{\mathrm{t}} \mathrm{E} \mathrm{dt}
$$

Considering $\mathrm{E}$ to be described by equation (2), it follows that:

$$
\begin{gathered}
e=\sum_{i=1}^{n-1}\left\{E_{i-1}\left(t_{i}-t_{i-1}\right)+\frac{\left(E_{i}-E_{i-1}\right)\left(t_{i}-t_{i-1}\right)}{m_{i}+1}\right\}+ \\
+E_{n-1}\left(t-t_{n-1}\right)+\frac{\left(E_{n}-E_{n-1}\right)\left(t_{n}-t_{n-1}\right)}{m_{n}+1}\left(\frac{t-t_{n-1}}{t_{n}-t_{n-1}}\right)^{m_{n}+1}
\end{gathered}
$$

where $\mathrm{n}$ is the number of periods of time t. Similar equations can be deduced for $f$ and $s$ : 


$$
\begin{gathered}
\mathrm{f}=\sum_{i=1}^{k-1}\left\{\mathrm{~F}_{\mathrm{i}-1}\left(\mathrm{~T}_{\mathrm{i}}-\mathrm{T}_{\mathrm{i}-1}\right)+\frac{\left(\mathrm{F}_{\mathrm{i}}-\mathrm{F}_{\mathrm{i}-1}\right)\left(\mathrm{T}_{\mathrm{i}}-\mathrm{T}_{\mathrm{i}-1}\right)}{\mathrm{M}_{\mathrm{i}}+1}\right\}+ \\
+\mathrm{F}_{\mathrm{k}-1}\left(\mathrm{t}-\mathrm{T}_{\mathrm{k}-1}\right)+\frac{\left(\mathrm{F}_{\mathrm{k}}-\mathrm{F}_{\mathrm{k}-1}\right)\left(\mathrm{T}_{\mathrm{k}}-\mathrm{T}_{\mathrm{k}-1}\right)}{\mathrm{M}_{\mathrm{k}}+1}\left(\frac{\mathrm{t}-\mathrm{T}_{\mathrm{k}-1}}{\mathrm{~T}_{\mathrm{k}}-\mathrm{T}_{\mathrm{k}-1}}\right)^{\mathrm{M}_{\mathrm{k}}+1} \\
\mathrm{~s}=\sum_{i=1}^{r-1}\left\{\mathrm{~S}_{\mathrm{i}-1}\left(\tau_{\mathrm{i}}-\tau_{i-1}\right)+\frac{\left(\mathrm{S}_{\mathrm{i}}-\mathrm{S}_{\mathrm{i}-1}\right)\left(\tau_{\mathrm{i}}-\tau_{\mathrm{i}-1}\right)}{\mu_{\mathrm{i}}+1}\right\}+ \\
+\mathrm{S}_{\mathrm{r}-1}\left(\mathrm{t}-\tau_{\mathrm{r}-1}\right)+\frac{\left(\mathrm{S}_{\mathrm{r}}-\mathrm{S}_{\mathrm{r}-1}\right)\left(\tau_{\mathrm{r}}-\tau_{\mathrm{r}-1}\right)}{\mu_{r}+1}\left(\frac{\mathrm{t}-\tau_{\mathrm{r}-1}}{\tau_{\mathrm{r}}-\tau_{\mathrm{r}-1}}\right)^{\mu_{\mathrm{r}}+1}
\end{gathered}
$$

where $\mathrm{k}$ and $\mathrm{r}$ are the number of periods of time $\mathrm{T}$ and $\tau$ for $\mathrm{f}$ and $\mathrm{s}$ respectively, and $\mathrm{M}$ and $\mu$ are exponential factors allowing the modification of the shape of the curves and $\mathrm{T}_{0}=\mathrm{t}_{0}=\tau_{0}=0$ and $\mathrm{t}_{\mathrm{n}-1}<\mathrm{t} \leq \mathrm{t}_{\mathrm{n}}$, $\mathrm{T}_{\mathrm{k}-1}<\mathrm{t} \leq \mathrm{T}_{\mathrm{k}}$ and $\mathrm{t}_{\mathrm{r}-1}<\mathrm{t} \leq \tau_{\mathrm{r}}$.

\section{DISCUSSION}

Soil formation due to rock weathering is affected by changes in rainfall amount, average temperatures, water infiltration rate, type of soil cover and other environmental or anthropic factors. The available data on soil formation rates are disperse and rare and the low rate of the process combined with the difficulty of its measurement at the soil-rock border makes the precise establishment not possible. Owens \& Watson (1979) found soil formation rates ranging from $0.004 \mathrm{~mm} \mathrm{y}^{-1}$ up to $0.011 \mathrm{~mm} \mathrm{y}^{-1}$ in Rhodesia. Wakastsuki \& Rasyidin (1992) found values ranging from 2,700 to 5,700 kg ha-1 $\mathrm{y}^{-1}$ in southwestern J apan. Miklos (1992) studying the formation of Alfisols and Oxisols due to biological activity in Brazil, obtained soil formation rates of approximately $0.5 \mathrm{~mm} \mathrm{y}$ Friend (1992), reviewing the literature on this subject found soil formation rates varying from $0.01 \mathrm{~mm} \mathrm{y}^{-1}$ to $8.5 \mathrm{~mm} \mathrm{y}^{-1}$, and considered values between $0.12 \mathrm{~mm} \mathrm{y}^{-1}$ and $0.25 \mathrm{~mm} \mathrm{y}^{-1}$ as normal. Soil depth increase as a consequence of sedimentation can be estimated considering the relative site position in the landscape.

However, to show some examples of the applicability of the equations soil depth increase rate, i.e. soil formation rate plus sedimentation rate, was assumed to be constant. Then, the substitution of equations (4) and (6) in (3) yields:

$$
\begin{aligned}
\Delta \mathrm{z} & =P\left(\mathrm{t}-\mathrm{t}_{0}\right)-\left[\sum_{\mathrm{i}=1}^{n-1}\left\{\mathrm{E}_{\mathrm{i}-1}\left(\mathrm{t}_{\mathrm{i}}-\mathrm{t}_{\mathrm{i}-1}\right)+\frac{\left(\mathrm{E}_{\mathrm{i}}-\mathrm{E}_{\mathrm{i}-1}\right)\left(\mathrm{t}_{\mathrm{i}}-\mathrm{t}_{\mathrm{i}-1}\right)}{\mathrm{m}_{\mathrm{i}}+1}\right\}+\right. \\
& \left.+\mathrm{E}_{\mathrm{n}-1}\left(\mathrm{t}-\mathrm{t}_{\mathrm{n}-1}\right)+\frac{\left(\mathrm{E}_{\mathrm{n}}-\mathrm{E}_{\mathrm{n}-1}\right)\left(\mathrm{t}_{\mathrm{n}}-\mathrm{t}_{\mathrm{n}-1}\right)}{\mathrm{m}_{\mathrm{n}}+1}\left(\frac{\mathrm{t}-\mathrm{t}_{\mathrm{n}-1}}{\mathrm{t}_{\mathrm{n}}-\mathrm{t}_{\mathrm{n}-1}}\right)^{\mathrm{m}_{\mathrm{n}}+1}\right]
\end{aligned}
$$

When defining the duration of a period in which erosion levels will have to change the degree of emergency of interference should be taken into account. If a water reservoir is being settled fast, a rapid interference may be needed to prevent water supply problems. In the case that no serious environmental problems or immediate productivity
Iosses are expected, but erosion rates are too high to maintain sustainable agriculture in a more distant future due to excessive soil depth loss, the time span to reduce erosion can and should be longer, avoiding technology non adoption problems (Fujisaka, 1994). L and tenure, markets, equipment and technological procedures may take several years to be changed, even if all other conditions and the consent from the farmers are provided for. The definition of the number of time intervals can be made previously or after the occurrence of a substantial change in the erosion tolerance conditioning criteria. The first period of time should always begin at present time with the actual erosion rate.

The erosion rate to be reached at the end of time period $i$ (target erosion rate, $E_{i}$ ) can be established by ecol ogical, economic, social or political criteria. Long term soil productivity maintenance (Pierce et al., 1984), control of sedimentation hazard in water reservoirs (Lo, 1994), impact of erosion associated contaminants (Clark II et al., 1985), effect of erosion control on farmers income (Timmons \& Amos, 1982) or soil formation (Alexander, 1988) may be used as parameters for $E_{i}$ definition.

For example, in high input tropical agricultural systems on deep and uniform Oxisols the best criteria for defining target erosion rate at short and medium periods of time may be environmental factors since depth loss is not an immediate problem. In moderately deep or shallow soils where any depth reduction is a loss of space for root devel opment, soil depth increase rate may bethe best target erosion rate. In developing regions, where food supply may be a critical social problem, the impact of erosion control costs on farmer's incomes, and consequently their economical survival, may fix short term target erosion rates. Considering a medium time period the environmental hazard associated to soil erosion may define the tolerable rate and in a more distant future the sustainable maintenance of the productivity. In an even more distant future soil depth increase rates will have to be the target for erosion rates, in order to maintain soil depth.

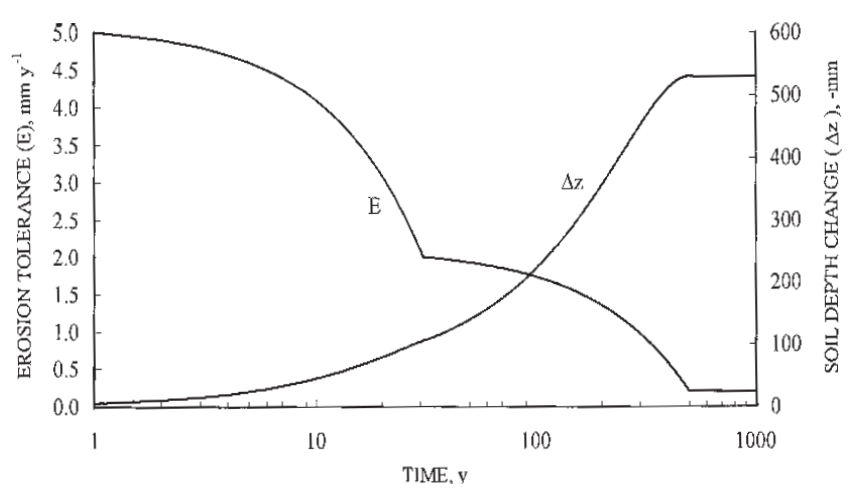

Figure 1. Shows an example of erosion tolerance determination considering the following values: $E_{0}=5.0 \mathrm{~mm} \mathrm{y}^{-1}, \quad P=0.2 \mathrm{~mm} \mathrm{y}^{-1}, \quad t_{1}=30 \mathrm{y}$, $E_{1}=2.0 \mathrm{~mm} \mathrm{y}^{-1}, t_{2}=500 \mathrm{y}, E_{2}=0.2 \mathrm{~mm} \mathrm{y}^{-1}$ and $m_{1}=m_{2}=m_{3}=1.00$. 
The applicability of the proposed model depends on the accuracy with which the equation parameters can be determined or estimated. Erosion rates usually cannot be measured but can be estimated by the Universal Soil Loss Equation USLE (Wischmeier \& Smith, 1978) or more recent models like the Water Erosion Prediction Project WEPP (Lane \& Nearing, 1989). These models can also be used to identify which practices will be needed to reduce soil erosion and allow economical evaluations on its applicability.

The soil depth change $(\Delta z, \mathrm{~mm})$ at the end of a 500 y period would be of $-524.4 \mathrm{~mm}$. I $\mathrm{n}$ this example the considered actual erosion $E_{0}$ of $5.0 \mathrm{~mm} \mathrm{y}^{-1}$ had to be reduced rapidly due to environmental hazard or productivity losses. A period of $30 \mathrm{y}$ was chosen to achieve the $E_{1}=2.0 \mathrm{~mm} \mathrm{y}^{-1}$ in order to perform the required production and economical adjustments. Within this first 30 y period the soil depth change was $-103.3 \mathrm{~mm}$, i.e. $20 \%$ of the total expected soil depth change after $500 \mathrm{y}$. The $\mathrm{E}_{1}=2.0 \mathrm{~mm} \mathrm{y}^{-1}$ was considered the erosion tolerance value at which no serious environmental or productivity loss problems are expected, but since this value is higher than the considered soil depth increase rate, the soil will become shallower. Therefore, this value can be tolerated only until a minimum soil depth is reached. In this example it was assumed that after 500 y the soil will have reached its minimum depth without restrictions for root development. From then on, soil erosion rates should not exceed soil depth increase rates in order to avoid more soil depth loss.

The soil depth changeat theend of the $500 \mathrm{y}$ period would be of $-216.9 \mathrm{~mm}$. In this example, the same actual conditions as in figure 1 were assumed, but the total soil depth change at time $t_{3}$ should be reduced. This may be dueto a shall ower soil, in which the minimum soil depth would be reached faster, or to different criteria resulting in an other estimation of minimum soil depth. The adoption of a second target erosion tolerance rate of $E_{2}=0.5 \mathrm{~mm} \mathrm{y}^{-1}$ at time $t_{2}=80$ y reduced the final soil depth change from $524.4 \mathrm{~mm}$ (F igure 1 ) to $-216.9 \mathrm{~mm}$ without changing the erosion rates from $t_{0}$ until $t_{1}=30 \mathrm{y}$.

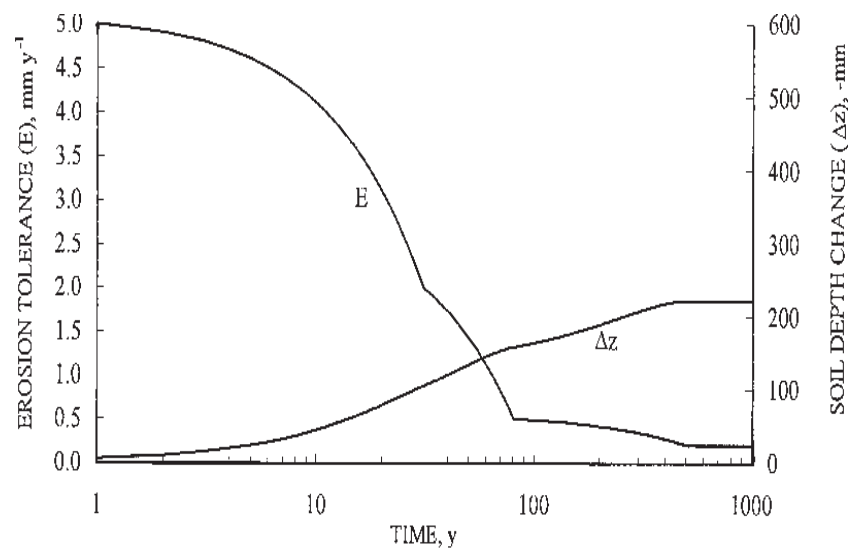

Figure 2 shows an example of erosion loss tolerance determination considering the following values: $E_{0}=5.0 \mathrm{~mm}^{-1}, \quad P=0.2 \mathrm{~mm}^{-1}, \quad t_{1}=30 \mathrm{y}_{1}$ $E_{1}=2.0 \mathrm{~mm} \mathrm{y}^{-1}, t_{2}=80 \mathrm{y}_{1} E_{2}=0.5 \mathrm{~mm} \mathrm{y}^{-1}, t_{3}=500 \mathrm{y}$, $E_{3}=0.2 \mathrm{~mm} \mathrm{y}^{-1}$ and $m_{1}=m_{2}=m_{3}=m_{4}=1.00$.

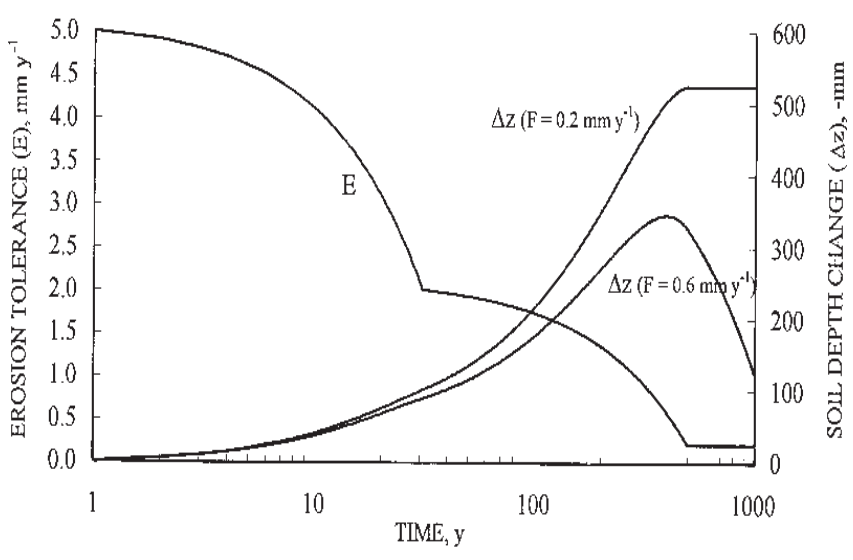

Figure 3 shows an example of erosion tolerance determination considering the following values: $E_{0}=5.0 \mathrm{~mm}^{-1}, t_{1}=30 \mathrm{y}, E_{1}=2.0 \mathrm{~mm} y^{-1}, t_{2}=500 \mathrm{y}$, $E_{2}=0.2 \mathrm{~mm} y^{-1}, m_{1}=m_{2}=m_{3}=1.00$ and two soil depth increase values, $P=0.2 \mathrm{~mm}^{-1}$ and $P=0.6 \mathrm{~mm} \mathrm{y}^{-1}$.

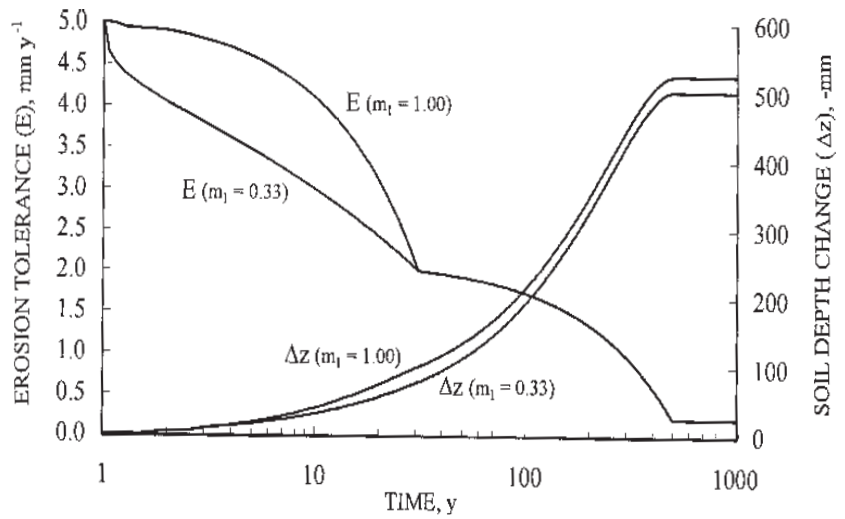

Figure 4 shows an example of erosion tolerance determination considering the following values: $E_{0}=5.0 \mathrm{~mm} \mathrm{y}^{-1}, \quad P=0.2 \mathrm{~mm} \mathrm{y}^{-1}, \quad t_{1}=30 \mathrm{y}$, $E_{1}=2.0 \mathrm{~mm} \mathrm{y}^{-1}, t_{2}=500 \mathrm{y}, E_{2}=0.2 \mathrm{~mm} \mathrm{y}^{-1}$ and different $m$ values, i.e. $m_{1}=m_{2}=m_{3}=1.00$ in the first case and $m_{1}=0.33$ and $m_{2}=m_{3}=1.00$ in the second.

The erosion tolerance will be the same and in a period of time of 30 years the difference in soil depth change is small. Considering $\mathrm{P}=0.2 \mathrm{~mm} \mathrm{y}^{-1}$ at the end of 100 years $\Delta z=-216 \mathrm{~mm}$ and with $\mathrm{P}=0.6 \mathrm{~mm} \mathrm{y}^{-1}$ the $\Delta z=-176 \mathrm{~mm}$ with a difference of $40 \mathrm{~mm}$. This difference may not be sufficient to cause substantial productivity losses within this time indicating that thesoil formation not necessarily has a great influence on short time decisions. I $\mathrm{n}$ a longer period of time, in this example 1,000 years, the difference in soil depth change became greater with $-124 \mathrm{~mm}$ if $\mathrm{P}=0.6 \mathrm{~mm}^{-1}$ and $-524 \mathrm{~mm}$ if $P=0.2 \mathrm{~mm} \mathrm{y}^{-1}$. In the case of $\mathrm{P}=0.6 \mathrm{~mm} \mathrm{y}^{-1}$, soil depth change reaches a maximum of $-345 \mathrm{~mm}$ after 397 years. After this, soil becomes deeper again since soil formation rate will be greater than soil erosion.

By considering a smaller $m_{1}$ value the curve decreased more rapidly, changing significantly the 
erosion tolerance values in a short period of time until $t_{1}$. However, the soil depth changeafter 500 y was al most the same indicating a low influence of the short time changes or decisions on irreversible soil degradation due to loss of soil depth for root development.

\section{CONCLUSIONS}

The definition of erosion tolerance through time according to the suggested equations allows the use of space-time-dependent variables like soil depth, present erosion rate, present and future social or economic scenarios and support the evaluation of soil degradation via soil depth change. This kind of approach is more appropriate for integrated and quantitative land evaluation procedures and compatible with data analysis by expert systems.

\section{FINAL CONSIDERATION}

Aiming the application of equation (9) by interested readers, a Microsoft Excel worksheet is available. To receive a copy of this worksheet, please contact the authors.

\section{REFERENCES}

ALEXANDER, E.B. Rates of soil formation: implications for soilIoss tolerance. Soil Sci., Baltimore, 145:37-45, 1988.

CLARK II, E.H., HAVERKAMP, J.A. \& CHAPMAN, W. Eroding soils. The off-farm impacts. Washington, The Conservation Foundation, 1985, 252p.

FRIEND, J.A. Achieving soil sustainability. J . Soil Wat. Cons., Ankeny, 47:156-157, 1992.
FUJ ISAKA, S. Learning from six reasons why farmers do not adopt innovations intended to improve sustainability of upland agriculture. Agric. Syst., Edinburgh, 46:409-425, 1994.

GROSSMAN, R.B. \& BERDANIER, C.R. Erosion tolerance for cropland: application of the soil survey data base. In: Editor, Determinants of erosion tolerance. American Society of Agronomy, 1982. p. 113-130.

LANE, L.J . \& NEARING, M.A. USDA - Water Erosion Prediction Project: Hillslope profile model documentation. Lafayette, Purdue Univ., 1989 (NSERL Report, 2)

LO, K.F.A. Quantifying soil erosion for the Shihmen reservoir watershed, Taiwan. Agric. Syst., E dinburgh, 45:105-116, 1994.

MCCORMACK, D.E., YOUNG, K.K. \& KIMBERLIN, L.W. Current criteria for determining soil loss tolerance. In: Determinants of soil loss tolerance. American Society Agronomy, 1982. p.95111.

MIKLOS, A.A. DE W. Biodynamique d'une coverture pédologique dans la région de Botucatu (SP). Paris, Université de Paris IV, 1992. 438p. (Tese de Doutorado)

OWENS, L.B. \& WATSON, J.P. Rates of weathering and soil formation on granite in Rhodesia, Soil Sci. Soc. Am. J., Madison, 43:160-166, 1979.

PIERCE, F.J ., LARSON, W.E. \& DOWDY, R.H. Soil loss tolerance: maintenance of long-term soil productivity. J. Soil Wat. Cons., Ankeny, 39:136-138. 1984.

SKIDMORE, E.L. Soil loss tolerance. In Determinants of soil loss tolerance. American Society Agronomy, 1982. p.87-93.

STAMEY, W.L. \& SMITH, R.M.A conservation definition of erosion tolerance. Soil Sci., Baltimore, 97:183-186. 1964.

TIMMONS, J.F. \& AMOS, O.M Economics of soil erosion control with application to T values. In Determinants of soil loss tolerance. American Society Agronomy, Madison, 1982. p.139151.

WAKASTSUKI, T. \& RASYIDIN, A. Rates of weathering and soil formation. Geoderma, Amsterdam, 52:251-263, 1992.

WISCHMEIER, W.H. \& SMITH, D.D. Predicting rainfall erosion losses -A guide to conservation planning (Washington, USDA, 1978. 58p. (Agr. Handbk, 537) 